\title{
POLA KESANTUNAN KALIMAT PERMINTAAN PADA MODEL DIALOG ENGLISH FOR WAITER PADA MAHASISWA STIPAR TRIATMA JAYA
}

\author{
I Made Agung Rai Antara ${ }^{1}$, Ni Putu Yunik Anggreni ${ }^{2}$ \\ STIPAR Triatma Jaya \\ agung.madrid@gmail.com¹, yunikangreni73@gmail.com²
}

\begin{abstract}
Abstrak
Bahasa Inggris merupakan bahasa yang sangat dibutuhkan dalam industri pariwisata. Salah satunya adalah bahasa inggris untuk pramusaji atau English for Waiter. Mahasiswa STIPAR Triatma Jaya merupakan calon pekerja di industri pariwisata yang harus mampu melakukan percakapan tentang reservasi sampai menangani pembayaran di restoran menggunakan bahasa inggris dengan baik dan sopan. Salah satu hal yang sangat penting diperhatikan dalam berkomunikasi adalah kesantunan. Kesantunan berbahasa sangat penting dipahami dan dipraktekkan karena hal ini dapat dijadikan sebuah pedoman untuk berinteraksi dengan tamu dari berbagai negara yang menggunakan bahasa Inggris sebagai media untuk berkomunikasi. Tujuan penelitian ini adalah mengetahui pola kesantunan kalimat permintaan pada model dialog bahasa Inggris mahasiswa manajemen food and beverage dan pola yang paling sering digunakan mahasiswa. Penelitian ini merupakan penelitian kualitatif. Metode pengumpulan data dilakukan dengan metode dokumentasi dan observasi, yaitu mendokumentasikan dialog yang sudah ditulis mahasiswa kemudian dianalisis secara deksriptif kualitatif. Hasil penelitian menunjukan bahwa pola kesantunan kalimat permintaan yang terdapat pada model dialog English for Waiter dilihat dari syntactic realization didominasi oleh modals dengan frekuensi penggunaan sebanyak 221 kali, diikuti oleh kalimat imperatif sebanyak 101 kali, interogatif. $78 \mathrm{x}$ dan deklaratif $32 \mathrm{x}$. Dilihat dari leksical realization, kata yang paling sering digunakan adalah like sebanyak 60 kata dan want sebanyak 6 kata.
\end{abstract}

\section{Kata Kunci : Bahasa Inggris profesi, kesantunan, kalimat permintaan}

\begin{abstract}
English is an important language needed in the tourism industry. One of the functions is to communicate with guests. English profession which usually used is English for waiters. In this skill, student must be able to ask and answer questions from handling a reservation to handling payment at a restaurant. One thing that is very important to notice in communication is politeness. Politeness in English language is very important for students because politeness can be used as a guide for interacting with people from various countries who use English as a medium for communication. The purpose of this study was to determine the politeness patterns of request sentences in the English dialogue model and the most used pattern. The dialogues were made by food and beverage management students. This research is qualitative research. The method of data collection was documentation method. It was done by documenting dialogues that have been made by students then they were analyzed using descriptive qualitative method. The results showed that the politeness patterns of request sentences contained in the English for waiter dialogue model were dominated by modals with a frequency of use of 221, followed by 101 imperative sentences, 78 interrogatives and 32 declarative sentences. Observed from lexical realization, the most words used was the word like (60) and want (6).
\end{abstract}

\section{Keywords: English Profession, Politeness, Request}

\section{PENDAHULUAN \\ Latar Belakang}

Bahasa di dunia terdiri dari berbagai macam jenis yang membuat bahasa sangat bervariasi. Salah satu bahasa yang menjadi bahasa Internasional adalah bahasa Inggris.
Bahasa Inggris merupakan bahasa yang digunakan dalam berbagai bidang misalnya pendidikan, olahraga , kesehatan dan lain sebagainya. Bahasa Inggris dapat dibedakan menjadi bahasa Inggris umum dan bahasa Inggris 
Profesi. Bahasa Inggris profesi sangat mutlak dikuasai seorang hotelier karena kompetensi mereka sangat ditunjang oleh kemampuan bahasa Inggris. Bahasa Inggris profesi adalah bahasa Inggris yang digunakan khusus pada suatu bidang keahlian atau profesi tertentu. Bahasa Inggris profesi memiliki perbedaan dengan bahasa Inggris umum yaitu pada kosakata atau vocabulary yang digunakan. Kemampuan dalam bidang Bahasa inggris profesi sangat penting digunakan dalam bidang keahlian masingmasing, misalnya bahasa inggris kedokteran memuat keahlian seorang dokter dalam mendiagnosa dan memberikan perawatan yang tepat bagi pasiennya. Bahasa Inggris dalam pariwisata menekankan kemampuan seseorang dalam menggunakan bahasa inggris pada bidang kantor depan, food and beverage dan lain sebagainya.

Selain itu, sebagai tujuan wisata, bahasa Inggris juga perlu dipertimbangkan untuk mendukung keberhasilan komunikasi dengan wisatawan asing, bahasa inggris merupakan salah satu aspek penting dalam komunikasi. Bahasa Inggris ada sebagai bahasa global, oleh karena itu bahasa Inggris secara luas dianggap sebagai bahasa global (Anggayana, Nitiasih \& Budasi, 2016). Bahkan dikenal sebagai bahasa internasional (Asriyani, Suryawati \& Anggayana, 2019). Komunikasi melibatkan pertukaran informasi yang disampaikan dalam ada dua jenis yaitu lisan dan tulisan (Antara, 2018).

Hal ini dilakukan untuk meminimalisir kesalahan pada aspek tata bahasa atau grammar bahasa Inggris, seperti penggunaan bentuk tenses dalam kalimat (Lindawati, Asriyani \& Anggayana, 2018). Tata bahasa atau dalam bahasa Inggris disebut dengan grammar adalah seperangkat peraturan yang terdapat dalam bahasa tertentu (Lindawati, Asriyani \& Anggayana, 2019). Memungkinkan mengembangkan kompetensi komunikatif mereka dalam empat keterampilan bahasa, yaitu keterampilan menyimak, berbicara, membaca dan menulis (Asriyani, Suryawati \& Anggayana, 2019). Walaupun di Indonesia terdiri dari berbagai dialek tidak menjadi halangan (Anggayana, Budasi \& Suarnajaya, 2014). Keterampilan berbicara (speaking skill) dalam bahasa Inggris merupakan keterampilan seseorang untuk menyampaikan hasrat dan pemikirannya kepada siapa saja secara lisan dengan menggunakan bahasa Inggris (Anggreni \& Antara, 2019).

Berbahasa Inggris saat ini telah menjadi percakapan yang sering dilakukan oleh wisatawan asing (Anggayana, Budasi, \& Kusuma, 2019). Dalam pelayanan tersebut, fasilitas dan kualitas pelayanan menjadi ujung tombak dalam hal pemberian kesan baik terhadap pelayanan (Anggayana \& Sari, 2018). Dalam industri pariwisata budaya dimasukkan ke dalamnya (Redianis, Putra \& Anggayana, 2019).

Sektor pariwisata mampu menyediakan ekonomi, sosial dan budaya yang bermanfaat bagi semua pelaku pariwisata stakeholders (Osin, Pibriari \& Anggayana, 2019). Tidak mengherankan bahwa industri pariwisata menjadi sektor ekonomi utama, di mana sebagian besar orang bekerja di industri pariwisata (Budasi \& Anggayana, 2019).

Pada dasarnya, kemajuan suatu bangsa sangat ditentukan oleh kualitas pendidikan penduduknya (Anggayani \& Osin, 2018). Sektor pariwisata terus digalakkan karena sektor ini merupakan andalan dalam menghasilkan pendapatan masyarakat serta devisa bagi negara (Suryawati, \& Osin, 2019). Dengan berkembangnya suatu industri pariwisata akan berpengaruh kepada meningkatnya pendapatan masyarakat sekitar obyek wisata serta terciptanya lapangan kerja (Osin, Kusuma, \& Suryawati, 2019).

Salah satu bahasa Inggris profesi yang sangat penting dalam dunia kerja adalah English for Waiter. English for waiter menekankan pada kemampuan berbahasa seorang waiter/waitress saat mereka melakukan percakapan mulai dari restaurant reservation sampai pada saat tamu membayar makanan. Pembelajaran bahasa Inggris for waiter sangat menekankan pada kesopanan atau politeness. Hal ini dapat dilakukan dengan berbagai macam ekspresi salah satunya 
adalah dengan bentuk kalimat permintaan atau request. Salah satu penelitian yang terkait dengan kesantunan berbahasa dilakukan oleh Xiamei (2014) yang meneliti kesopanan pramusaji pada dua jenis restoran yaitu restoran yang tergolong low grade dan middle grade. Hasil penelitian menyimpulkan bahwa pada restoran yang tergolong kelas menengah ada lima karakteristik kesopanan yang ditemukan. Pertama, seorang waiter/waitress pada restoran kelas menengah menggunakan penanda kesopanan pada saat tamu memasuki restoran atau selama penyajian makanan, salah satunya adalah dengan kata please, sedangkan pada restoran kelas bawah mereka tidak mengggunakan hal tersebut. Pada restoran kelas menengah waiter/waitress menggunakan kata ganti kehormatan untuk menyapa tamu, sedangkan pada restoran kelas bawah mereka menggunakan kata kamu. Mereka menghindari menyampaikan rekomendasi pada pelanggan mereka, sedangkan pada restoran kelas menengah mereka lebih memilih menyampaikan rekomendasi makanan untuk tamu. Waiter atau waitress berperilaku sangat baik pada saat melayani tamu sedangkan pada restoran kelas bawah tidak berperilaku dengan tepat.

Mahasiswa STIPAR Triatma Jaya Jurusan food and beverage dipersiapkan untuk bekerja pada hotel bidang lima atau restoran yang termasuk middle grade ke atas. Maka dari itu kesantunan berbahasa, terutama bahasa Inggris sangat penting untuk dikuasai sehingga mereka bisa memberikan pelayanan yang maksimal kepada tamu. Maka dari itu penelitian tentang pola kesopanan pada kalimat permintaan sangat penting untuk dilakukan.

\section{Masalah Penelitian}

1. Bagaimanakah pola kesantunan kalimat permintaan yang digunakan mahasiswa Manajemen Food and Beverage untuk mengekspresikan kesantunan berbahasa di STIPAR Triatma Jaya?
2. Pola kalimat permintaan apa sajakah yang paling sering digunakan mahasiswa Manajemen food and beverage dalam mengekspresikan kesantunan berbahasa di STIPAR Triatma Jaya?

\section{Tujuan Penelitian}

Tujuan penelitian ini adalah mengetahui pola kalimat permintaan yang digunakan mahasiswa Manajemen Food and Beverage untuk mengekspresikan kesantunan berbahasa di STIPAR Triatma Jaya dan pola kalimat permintaan yang paling sering digunakan mahasiswa Manajemen food and beverage dalam mengekspresikan kesantunan berbahasa di STIPAR Triatma Jaya.

\section{Landasan Teori}

\section{Dialog}

Dialog adalah suatu bentuk percakapan antara dua orang atau lebih dimana terjadi tanya jawab tentang suatu topik tertentu. Alwi, Hasan dkk (2003:261) menyatakan bahwa dialog adalah sebuah bentuk cerita serta karya tulis yang disajikan dalam bentuk percakapan.

\section{Kesantunan}

Kesantunan dapat didefinisikan sebagai sebuah usaha untuk mengoptimalkan keuntungan dan meminimalkan kerugian petutur (Leech dalam Mahmud 2019). Menurut Brown dan Levinson (1987) kesopanan merupakan tindakan regresif yang diambil untuk mengimbangi efek mengganggu dari tindakan yang mengancam wajah. Holmes (1995) menjelaskan bahwa kesopanan sangat konsisten dengan rasa hormat, maka dari itu kesantunan merupakan suatu bentuk perilaku yang tidak menganggu dan memaksa.

\section{Pola kesantunan dalam kalimat permintaan}

Kalimat permintaan adalah kalimat yang meminta orang lain melakukan sesuatu. Aturan utama dari kalimat permintaan adalah bahwa peminta meminta kesadaran bahwa sebuah tindakan sedang diminta darinya. Hal ini dapat 
diperoleh dengan berbagai macam cara.

Cara tersebut adalah syntactical realization dan lexical realization (Saddock dalam Aubed, 2012).

\section{Syntactical realization}

Pola ini dapat dijabarkan menjadi tipe kalimat imperatif, introgatif,deklaratif dan modal auxiliary

\section{Tipe kalimat imperatif}

Kalimat imperatif adalah kalimat yang berisi perintah. Kalimat imperatif bisa digunakan untuk meminta orang lain melakukan sesuatu. Pada kalimat bahasa Inggris, contohnya adalah give him your watch. Seringkali untuk membuat kalimat menjadi lebih sopan sering digunakan atau ditambahkan kata please misalnya give him your watch please atau please give him your watch.

\section{Tipe kalimat interogatif}

Kalimat interogatif atau kalimat tanya dapat digunakan sebagai polite request namun tipe ini tidak menggunakan modal auxiliary.

Contoh.
a. Have you got a car?
b. Do you have an extra piece of paper?
c. Do you have some papers?
d. Why don't you cook for lunch?

\section{Tipe kalimat deklaratif}

Kalimat deklaratif adalah kalimat yang berisi informasi tentang suatu hal. Kalimat ini sering disebut kalimat berita. Contohnya I am very hungry. Secara tidak langsung kalimat ini menyatakan suatu permintaan untuk membawakan makanan. This class is so hot. Demikian pula dengan kalimat ini yang menyatakan secara tidak langsung meminta untuk menghidupkan $A C$ atau hal lainnya yang membuat kamar menjadi lebih dingin misalnya membuka jendela. You didn't tell mom that I broke the window did you? Permintaan untuk tidak mengatakan pada ibu bahwa dia memecahkan jendelanya.

\section{Modal Auxiliary}

Modal auxiliary seperti will, would, can, could, may bisa digunakan untuk mengekspresikan permintaan (Austin dalam Aubed, 2012).

Contohnya:
a. Could you spell your name please?
b. Can you tell me about yourself?
c. Will you pass me the sugar?
d. May I borrow your dictionary?
e. Would you help me with this task?
f. You might make less noise.

\section{Lexical Realization}

Realisasi leksikal dibagi menjadi dua tipe, tipe pertama adalah

1. Kata kerja: Kategori pertama

Pada kategori pertama, pilihan lexical atau kata yang digunakan adalah "appeal, ask, favour, like, mind, oblige, request, want.
a. Can I appeal to you for help?
b. I ask you to clean the car
c. Will you favor us with a very nice song?
d. I would like to see this film
e. Would you mind closing the window?
f. Could you oblige me with cigarette?
g. I request you to send some book of pragmatics
h. I want two nice shirts
i. I wish you would stop smoking

2. Kata Kerja: Kategori kedua Kategori kedua leksikal yang bisa digunakan adalah appreciate, thank, trouble, possibly, and wonder.
a. I would appreciate your help
b. I will thank you for the offer
c. Could I trouble you to pass the salt?
d. I wonder If you wouldn't mind dropping me home.




\section{METODE}

Pendekatan penelitian ini adalah kualitatif. Pendekatan kualitatif yaitu pendekatan penelitian yang bermaksud untuk memahami fenomena tentang hal yang dialami oleh subjek penelitian dengan cara deskripsi berupa kata-kata, misalnya perilaku, persepsi, motivasi, tindakan dll secara holistik (Moleong, 2005:6). Data dikumpulkan melalui metode dokumentasi dan observasi. Data dialog diperoleh dari 25 tulisan mahasiswa pada kelas MFB C. Fokus penelitian ini adalah pola kesantunan dalam request atau kalimat permintaan serta pola yang paling sering digunakan dalam membuat kalimat percakapan English for Waiter. Data disajikan secara formal dan informal yaitu melalui penjelasan melalui tabel dan uraian kalimat.

\section{HASIL DAN PEMBAHASAN}

Tabel 4.1 Pola Kesantunan dalam Kalimat Permintaan.

\begin{tabular}{|c|c|c|c|}
\hline $\begin{array}{l}\mathrm{N} \\
\mathrm{O}\end{array}$ & $\begin{array}{c}\text { Pola } \\
\text { Kesantuna } \\
\text { n dalam } \\
\text { Request }\end{array}$ & Tipe & $\begin{array}{c}\text { Frekuensi } \\
\text { Penggunaa } \\
\mathrm{n}\end{array}$ \\
\hline \multirow[t]{4}{*}{1} & \multirow[t]{4}{*}{$\begin{array}{l}\text { Syntactical } \\
\text { Realization }\end{array}$} & Imperatif & 101 \\
\hline & & Deklaratif & 32 \\
\hline & & Interogatif & 78 \\
\hline & & Modals & 221 \\
\hline \multirow[t]{10}{*}{2} & \multirow[t]{10}{*}{$\begin{array}{l}\text { Lexical } \\
\text { Realization }\end{array}$} & $\begin{array}{c}\text { Kategori } \\
1\end{array}$ & \\
\hline & & Appeal & 0 \\
\hline & & Ask & 0 \\
\hline & & Favour & 0 \\
\hline & & Like & 30 \\
\hline & & Mind & 0 \\
\hline & & Oblige & 0 \\
\hline & & Request & 0 \\
\hline & & Want & 6 \\
\hline & & $\begin{array}{c}\text { Kategori } \\
2\end{array}$ & 0 \\
\hline
\end{tabular}

\begin{tabular}{|c|c|c|}
\hline \multirow{4}{*}{} & $\begin{array}{c}\text { Appreciat } \\
e\end{array}$ & 0 \\
\cline { 3 - 4 } & Thank & 0 \\
\cline { 3 - 4 } & Trouble & 0 \\
\cline { 2 - 3 } & Wonder & 0 \\
\hline
\end{tabular}

Pola kesantunan kalimat permintaan yang dihasilkan oleh mahasiswa Triatma Jaya jurusan Manajemen Food and Beverage dapat dilihat pada contoh berikut ini.

\section{Syntactical Realization}

Pola syntactical realization yang ditemukan pada tulisan mahasiswa adalah modals, imperatif, interogatif dan deklaratif. Contoh dapat dilihat pada kalimat berikut ini.

\section{a. Modals}

\section{Contoh}

- I would like to book a table please

- What day would that be Sir?

- What time would you arrive?

- Would you like to follow me please?

- May I pour your red wine please?

- May I clear up now?

- Can I speak to the headwaiter please?

- Could you spell your name please?

Kata would pada kalimat diatas digunakan oleh tamu untuk menyatakan permintaan terhadap sesuatu. Apakah keinginan untuk memesan meja, meminta informasi tentang hari, waktu dan sebagainya. Kata would merupakan salah satu cara untuk menjadikan kalimat lebih sopan. Kata may digunakan untuk ask for permission atau meminta meminta ijin untuk melakukan sesuatu. Can dan could juga digunakan untuk membentuk kalimat permintaan. Kata could lebih sopan dari kata can. Can biasanya digunakan pada kalimat formal, namun pada 
penggunaan kata can, kalimat tersebut menjadi lebih sopan dengan penggunaan kata please.

\section{b. Imperatif \\ Contoh}

- Please enjoy your food

- Please enjoy your main course

- Have a seat please

- Follow me please

- Please sit down

- Please enjoy your food

- Please wait a moment

- Please wait

Pada kalimat imperatif yang ditulis siswa untuk mengungkapkan permintaan sebagian besar menggunakan kata please untuk menyatakan kesopanan. Please merupakan penanda kesopanan yang paling terlihat untuk memperhalus pengenaan terhadap permintaan yang diucapkan (Silianou, 1999)

\section{c. Interogatif}

\section{Contoh}

- What name was that please?

- How about your grilled sirloin steak?

- Have you any reservation before?

- Have you finished with the dessert?

- Have you finished?

- Is the food still available?

Pada kalimat diatas,mahasiswa menggunakan kalimat tanya untuk membentuk kalimat permintaan. Beberapa bentuk kalimat tanya yang digunakan adalah yes/no questions. Pada contoh kalimat How about your grilled sirloin steak? mengekspresikan sebuah permintaan untuk memberikan penilaian terhadap makanan yang dihidangkan. Pada kalimat have you finished with the dessert?
Pada kalimat ini, pembicara meminta informasi tentang dessert. Kalimat ini secara tidak langsung juga meminta untuk clear up the dessert jika sudah selesai.

\section{d. Deklaratif Contoh.}

- I have reservation under the name of Leo

- This is your Bill

- This is your orange squash

- $\quad$ This is the menu

- This is your orange juice

- Here is your table

- $\quad$ This is the menu madam

- $\quad$ This is the menu

- This is your meal

Pada kalimat diatas, kalimat deklaratif dapat digunakan sebagai kalimat permintaan. Pada kalimat diatas, secara tidak langsung kalimat tersebut meminta pendengar melakukan sesuatu. Misalnya pada kalimat I have reservation under the name of Leo. Pembicara secara tidak langsung ingin pendengar memeriksa atau mengecek reservasi yang sudah dilakukan oleh pembicara.

\section{Lexical Realization}

Sintaksis leksikal diwujudkan mahasiswa dengan penggunaan kata like dan want. Contoh

\section{a. Like}

- I would like to book a table for tonight

- Would you like to follow me please?

- Which one would you like for starter Mrs Leo?

- I would like to check your reservation 
- I would like to order 1 chicken Hawaian

\section{b. Want}

- Do you want the food to go out together?

- I want one Cesar salad

- I want to order one orange juice

- I want to have dinner

- I want to order red wine

4.2 Tipe yang paling sering digunakan mahasiswa untuk mengekspresikan kesantunan berbahasa dalam pembelajaran bahasa Inggris profesi di STIPAR Triatma Jaya adalah tipe modals dengan frekuensi sebanyak 221, kedua diikuti oleh kalimat imperatif sebanyak 101, ketiga interogatif sebanyak 78 dan paling sedikit ditemukan adalah kalimat deklaratif sebanyak 32 . Tipe leksikal yang paling banyak ditemukan hanya dua yaitu kata like dan want. Tipe like mendominasi sebanyak 30 pemakaian sedangkan pola want hanya ditemukan sebanyak 6 kata.

\section{PENUTUP}

Berdasarkan pembahasan yang sudah dilakukan, dapat disimpulkan bahwa Kesopanan berbahasa Inggris sangat penting dalam pembelajaran bahasa Inggris Profesi. Mahasiswa Manajemen Food and Beverage di STPAR Triatma Jaya sudah mampu membuat model dialogue English for Waiter dengan baik. Dialog yang disusun berisi prinsip dasar kesantunan berbahasa seperti modals dan please. Kalimat permintaan yang ditulis mahasiswa didominasi oleh penggunaan modals sebanyak $221 \times$ diikuti oleh kalimat imperatif 101, interogatif sebanyak 78 dan kalimat deklaratif sebanyak 32 . Dari segi leksikal kata yang paling sering dipakai adalah kata like sebanyak 60 kata dan 6 kata want. Kata like seringkali dikombinasikan dengan modal would untuk membentuk request dalam bahasa Inggris.

\section{DAFTAR PUSTAKA}

Alwi, Hasan, dkk. 2003. Kamus Besar Bahasa Indonesia. Jakarta: Balai Pustaka

Anggayana, I. A., Budasi, I. G., \& Kusuma, I. W. (2019). Social Dialectology Study of Phonology in Knowing English Student Speaking Ability. (P. Robertson, Ed.) The Asian EFL Journal, 25(5.2), 225-244.

Anggayana, I. W. A., \& Sari, N. L. K. J. P. (2018). Kemampuan Berbicara Bahasa Inggris Mahasiswa Akomodasi Perhotelan: sebuah Kajian Fonologi. Jurnal Manajemen Pelayanan Hotel, 1(1), 8-14.

Anggayana, I. W. A., Budasi, I. G., Lin, D. A., \& Suarnajaya, I. W. (2014). Affixation of bugbug dialect: A Descriptive Study. Jurnal Pendidikan Bahasa Inggris undiksha, 1(1).

ANGGAYANA, I. W. A., NITIASIH, D. P. K., BUDASI, D. I. G., \& APPLIN, M. E. D. (2016). Developing English For Specific Purposes Course Materials for Art Shop Attendants and Street Vendors. Jurnal Pendidikan Bahasa Inggris Indonesia, 4(1).

Anggayani, N. W., \& Osin, R. F. (2018). Pengaruh Service Performance Terhadap Nilai Sekolah Kepuasan Dan Loyalitas Pelajar Pada Smk Pariwisata Triatma Jaya Tabanan. Jurnal Manajemen Pelayanan Hotel, 1(1), 28-35.

Anggreni, N. P. Y., \& Antara, I. M. A. R. (2019). Pembelajaran Keterampilan Berbicara Talks as Interacion Dalam Bahasa Inggris Profesi Melalui Guided Conversation Di Stipar Triatma Jaya, Bali. Jurnal Manajemen Pelayanan Hotel, 3(1), 45-73. 
Antara, I. M. A. R. (2018). Error Analysis dalam Penulisan Menu Ditinjau dari Surface Strategy Taxonomy pada Mahasiswa Stipar Triatma Jaya. Jurnal Manajemen Pelayanan Hotel, 2(1), 10-19.

Asriyani, R., Suryawati, D. A., \& Anggayana, I. W. A. (2019). PENERAPAN TEKNIK ROLE PLAY DALAM MENINGKATKAN KOMPETENSI BERBICARA BAHASA INGGRIS SISWA KELAS SEBELAS

KEANEKARAGAMAN

PERSONALITY TYPES DI SMK PARIWISATA TRIATMA JAYA BADUNG. LITERA: Jurnal Litera Bahasa Dan Sastra, 5(2).

Asriyani, R., Suryawati, D. A., \& Anggayana, I. W. A. (2019, August). USING ROLE PLAY TECHNIQUES IN IMPROVING ENGLISH SPEAKING COMPETENCY ON THE PERSONALITY TYPES. In International Conference on Cultural Studies (Vol. 2, pp. 44-48).

Aubed, M. 2012. Polite Request in English and Arabic: A Comparative Study and Theory and Practice in Language Studies,.2 (5): 916-922

Brown, P., \& Stephen, C.L. (1987). Politeness: Some universals in language use. Cambridge: Cambridge University Press.

Brown, Penelope, Levinson, Stephen C. (1987). Politeness Some Universals in Language Usage. Cambridge University Press.

Budasi, I. G., \& Anggayana, I. A. (2019). Developing English for Housekeeping Materials for Students of Sun Lingua College Singaraja-Bali. The Asian EFL Journal, 23(6.2), 164-179.
Holmes, J. (1995). Women, men, and politeness. London and New York:Longman

Horn,R.L. dan Ward,G. 2007. The Handbook of Pragmatics. Blakwell Publishing.

Lestari, Dwi Permata. 2013. An Analysis of Politeness Language Patterns in Request Used in the English Textbooks of Second Grade of Junior High School. Thesis. English Education Study Program of Language and Art Department. Bengkulu: Universitas Bengkulu

Lindawati, N. P., Asriyani, R., \& Anggayana, I. W. A. (2018). KEMAMPUAN MENULIS KARANGAN DIALOG MELALUI MODEL PEMBELAJARAN KOOPERATIF TIPE THINK-PAIRSHARE PADA MAHASISWA JURUSAN TATA HIDANGAN DI AKADEMI KOMUNITAS MANAJEMEN PERHOTELAN INDONESIA. SINTESA.

Lindawati, N. P., Asriyani, R., \& Anggayana, I. W. A. (2019). MODEL KOOPERATIF THINKPAIR-SHARE DALAM MENINGKATKAN KEMAMPUAN MENULIS KARANGAN DIALOG BAHASA INGGRIS MAHASISWA AKADEMI KOMUNITAS MANAJEMEN PERHOTELAN INDONESIA. LITERA: Jurnal Litera Bahasa Dan Sastra, 4(1).

Mahmud, M. (2018) The use of Politeness strategies in the classroom context by English university students, Indonesian Journal of applied linguistics,8,597-606.

Moleong J.Lexy. 2005. Metodologi Penelitian Kualitatif. Bandung: Remaja Rosdakar

Osin, R. F., Kusuma, I. R. W., \& Suryawati, D. A. (2019). STRATEGI PENGEMBANGAN 


\section{OBJEK WISATA KAMPUNG TRADISIONAL BENA KABUPATEN NGADA-FLORES NUSA TENGGARA TIMUR (NTT). Jurnal Ekonomi dan Pariwisata, 14(1).}

Osin, R. F., Pibriari, N. P. W., \& Anggayana, I. W. A. (2019, August). BALINESE WOMEN IN SPA TOURISM IN BADUNG REGENCY. In International Conference on Cultural Studies (Vol. 2, pp. 35-38).

Peng, X.M. (2014). Politeness in Restaurants of Different Grades. Studies and Literature and Language, 8(3), 33-39.

RatihAsti (2016) Interlanguage Pragmatics of Request by IFL (Indonesian as a Foreign Language) Learners. Thesis thesis, Universitas Muhammadiyah Surakarta

Redianis, N. L., Putra, A. A. B. M. A., \& Anggayana, I. W. A. (2019, August). EFFECT OF CULTURE ON BALINESE LANGUAGE USED BY EMPLOYEE HOTELS FOR FOREIGN TRAVELERS IN THE SOCIOLINGUISTIC

PERSPECTIVE. In International Conference on Cultural Studies (Vol. 2, pp. 39-43).

Saddock, J.M. (1974). Towards a Linguistic Theory of Speech Act, New York: Academic Press

Silinou, 1999. Politeness Phenomena in England and Greece. A CrossCultural Perspective. Oxford.Oxford University Press

Suryawati, D. A., \& Osin, R. F. (2019). Analisis Menu untuk Menentukan Strategi Bauran Pemasaran pada Bunut Café di Hotel White Rose Legian Kuta. Jurnal Manajemen Pelayanan Hotel, 3(1), 29-35. 